University of Massachusetts Amherst

ScholarWorks@UMass Amherst

Phonological milestones for African American English-speaking children learning Mainstream American English as a second dialect

\author{
Barbara Zurer Pearson \\ Shelley L. Velleman \\ Timothy J. Bryant \\ Tiffany Charko
}

Follow this and additional works at: https://scholarworks.umass.edu/aae_delv

Pearson, Barbara Zurer; Velleman, Shelley L.; Bryant, Timothy J.; and Charko, Tiffany, "Phonological milestones for African American English-speaking children learning Mainstream American English as a second dialect" (2009). Language, Speech, and Hearing Services in Schools. 3.

https://doi.org/10.1044/0161-1461(2008/08-0064)

This Article is brought to you for free and open access by the NIH Working Groups on African American English $(\mathrm{AAE})$ at ScholarWorks@UMass Amherst. It has been accepted for inclusion in Publication of the DELV tests and beyond by an authorized administrator of ScholarWorks@UMass Amherst. For more information, please contact scholarworks@library.umass.edu. 


\title{
Phonological Milestones for African American English-Speaking Children Learning Mainstream American English as a Second Dialect
}

\author{
Barbara Z. Pearson \\ Shelley L. Velleman \\ University of Massachusetts, Amherst \\ Timothy J. Bryant \\ University of New Hampshire, Durham \\ Tiffany Charko \\ Agawam Public Schools, city, state
}

AQ1

$\mathrm{n}$ contrast to the majority of Mainstream American English (MAE) learners in the United States, African -American-English (AAE)-speaking children are learning two dialects. The majority of African American (AA) children come to school speaking $\mathrm{AAE}$ as their primary dialect (Craig, Thompson, Washington, \& Potter, 2003; Jackson \& Pearson, 2004). Once in elementary school, however, most of their education will be in the medium of MAE, so as they progress through school, they speak more MAE. To the extent that MAE is a second dialect for them, normative standards for the acquisition of its phonology must be adapted to take into account differences between the two dialects

According to Stockman (2006), Luelsdorff (1975), and Green (2002), among others, the consonant inventory of AAE is largely the same as the inventory of other dialects of English, with the exception of the interdental fricatives ( $\partial$ and $\theta$ ), which are generally realized differently in $\mathrm{AAE}$. However, beyond this similarity in the segments, differences in phonotactic patterns--that is, syllable structure, stress patterns, and co-occurrence restrictions among segments-may produce differences in how often the phonetic
ABSTRACT: Purpose: This study provides milestones for phonolog. ical development in African American English (AAE) speakers who are learning Mainstream American English (MAE) as a second dialect Method: The Dialect Sensitive Language Test (DSLT, II Seymour, I. Roeper, \& I. O. de Villiers, 2000) was administered to a nationwide sample of typically developing children ages 4 through 12:537 speakers of $A A E$ as a first dialect and 317 speakers of MAE as a first dialect DSLT items tested all consonant segments and many clusters of MAE in initial and final position The age at which each dialed group reached $90 \%$ criterion for each segment in each position was conpared

Results: Several phonetic elements that are contrastive between the dialects (i.e. differentiate the dialects) in word-final position
Were found to be similar in the 2 groups in onset position. Only $/ 0$ was contrastive in both positions. We confirm the later acquisition of certain phonological segments and structures by AAE speakers compared to MAE speakers and report their earlier mastery of other elements of MAE phonology

Conclusion; Both segmental and phonotactic development show different trajectories for AAE and MAE Thus, initial diagnosis of impairment for AAE children should focus only on mastery of noncontrastive segments and structures that share a similar developpental profile for the 2 dialect groups

KEY WORDS: speech and assessment, multicultural issues, evidence-based practice, African American English 
elements are used. As a result, different phonotactic patterns may alter the developmental timetable even for the same segments when MAE is spoken as a second dialect. Until norms for MAE based on observations of typically developing AAE-speaking children are created, such children are at risk for misdiagnosis of their phonological abilities.

As pointed out by Stockman (1996, 2006), comprehensive research on AAE-speaking children's phonological development in MAE has been limited. Most studies have either described differences between the performance of child AAE and MAE speakers on standardized tests that have been normed on mainly first-dialect speakers of MAE (Haynes \& Moran, 1989; Ratusnik \& Koenigsknecht, 1976; Seymour \& Seymour, 1981) or focused on the development of a specific segment or set of segments, or on the frequency of phonological processes (Haynes \& Moran, 1989; Moran, 1993; Seymour, Green, \& Huntley, 1991; Stockman, 1993). In general, more attention has been paid to MAE-AAE differences (Craig et al, 2003; Craig \&Washington, 2004) and much less attention to the range of normal variability among AAE speakers. Normative data on shared elements of the phonologies is noticeably absent (Stockman, 1996). One exception is Stockman's 2006 atticle, which seeks to establish what she calls a phonological "minimal competence core," that is, criteria for typical phonological development for 3-year-old AAE-learning children. However, that work is based on transcripts from only seven preschool children and remains preliminary.

The current study extends Stockman's work to a larger group of children and a larger range of ages. It proposes criterion-referenced milestones for phonological development based on a nationwide sample of typically developing AA learners of MAE as a second dialect, ages 4 to 12 years. The investigation encompassed all of the consonants of English and many consonant clusters by word position, initial and final. A comparison group of first-dialect MAE speakers provided points of reference for the second-dialect learners' development. We examined in particular whether the influence of the adult target dialects, $A A E$ and MAE, can be seen in the rate of acquisition of specific consonants and consonant clusters, and if so, whether the differences in frequency and function of specific segments and clusters in the respective dialects affect the order of acquisition as well. We probed which quantitative differences are found only in some contexts (e. $g_{\text {. }}$, only in final position, or in specific lexical environments) and which may be observed throughout the phonological system. The primary goal was to supplement the phonological milestone information available to speech-language pathologists (SLPs) in standard textbooks with milestones that are appropriate to children who are learning $\mathrm{AAE}$ as a first dialect.

The article is organized as follows: First, we establish general patterns of phonological development that one must consider in examining the two dialects, $\mathrm{AAE}$ and MAE, for differences that might be expected to give rise to different rates of acquisition. Next, using the findings from a large-scale standardization of a dialectsensitive phonology probe, we propose comprehensive milestones that have thus far been lacking for AAE-speaking children learning MAE, verifying the importance of taking word position into account. Then, we examine the effects on production of examiner ethnicity and of a phone's occurrence within an initial unstressed syllable. Finally, we establish that dialect differences can be identified as young as age 4

\section{General Patterns in Typical Phonological Development}

Normative guidelines that are used for identifying children for speech services, such as developmental milestones that are provided in standard textbooks in the field, report both the error patterns and the order of acquisition of various segments and phonotactic structures (e.g., closed syllables, clusters, unstressed syllables). Typical segmental (phonetic) error patterns include substitutions such as fronting of velars to alveolar position, stopping of fricatives, gliding of liquids, simplification of affricates to either stops or fricatives, and distortions. Not surprisingly, such error patterns tend to affect later developing phonemes, such as the "late 8 " consonants $\int, \theta, s, z, \partial, 1, x, 3$ (Shriberg 1993), to a much greater extent than they do earlier mastered segments. Typical structural (phonotactic) mismatches include consonant deletion, weak syllable deletion, epenthesis (e. g., [bəlu] for blue), and consonant cluster reduction.

Studies of consonant acquisition in MAE indicate that the majority of earlier developing consonants (e.g., most stops, plus /f/, $/ z /$, and $/ 1 /$ ) are acquired first in initial position, with only a few stops and nasals that tend to be mastered in final position first (e.g., $/ \mathrm{m} /, / \mathrm{p} /, / \mathrm{g} /$ ) (Smit, Hand, Freilinger, Bernthal, \& Bird, 1990). Most later developing consonants are mastered at approximately the same age for both positions (Smit et al., 1990). However, more detailed smaller scale studies indicate that final position may favor the development of fricatives (Edwards, 1996; Farwell, 1977; Ferguson \& Farwell, 1975) and velars (Stoel-Gammon, 1996; Vihman \& Hochberg, 1986) in many children.

A similar trend has been observed for the mastery of consonant clusters. A substantial number of both initial and final clusters can be expected by age 4 (Peña-Brooks \& Hegde, 2000; Stockman 2006). Although most clusters occur either initially or finally, a few, such as [sp], [sk], and [st], are found in both positions. Mastery of these $\mathrm{sC}$ clusters is observed between 4 and 6 years of age in initial position (McLeod, van Doorn, \& Reed, 2001b) in contrast to final position where, according to standard texts, full mastery is not expected until around age 8 (Peña-Brooks \& Hegde, 2000) Sonority, syllable weight, and word position are all key factors in cluster acquisition among MAE-learning children aged 18 months to 3 years (Chambless, 2006). In studies of MAE, the very earliest clusters acquired tend to be homorganic final ones with large sonority differences, such as [-nt], although some key morphologically complex clusters such as [-ts] may also be early despite smaller sonority differences (Dyson, 1988; Kirk \& Demuth 2003; McLeod, Van Doorn, \& Reed, 2001a; Watson \& Scukanec, 1997)

Considering phonetics and phonotactics together is critical As segments are acquired in different word positions, phonetic and phonotactic complexity may trade off. That is, the child may not produce a mastered consonant in a more complex word shape or, in contrast, may acquire a consonant first in a cluster due to facilitating contextual effects (Kent, 1982). Many developmental phonological patterns relate specifically to structure acquisition (e g., simplified consonant clusters, final consonant or weak syllable omission; Ingram, 1978). The difference between initial and final position in children's inventories is so great for most languages that separate developmental guidelines are generally provided for each word position (e g., for MAE, see Smit et al, 1990). Therefore, guidelines for AAE-speaking learners of MAE must also include separate criteria that take word position into account. 


\section{Comparison of the Target Dialects}

Phonological differences between the target dialects, AAE and MAE, have been well described since the late 1960s when AAE was recognized as a rule-governed linguistic system and not just a random corruption of the standard dialect. (See Green, 2002; Labov, 1970; Luelsdorff, 1975.) Most sources treat both dialects as if they were "monolithic" (i.e., the same throughout the United States). This is not true of either dialect (e.g., Jackson \& Pearson, 2004), but geographic variations are not our focus here. Given that our participants were sampled from all different regions, it is presumed that our results reflect commonalities among varieties of AAE.

Seymour and Seymour (1977) pointed out that although many areas of the two dialects are shared, or "noncontrastive," a significant portion are distinct, or "contrastive." Many of the relevant distinctions between the two dialects are differences of quantity, that is, frequency or variability of occurrence. It has been shown for other dialect groups, such as the Tyneside variety (found in the Newcastle region of NE England), that children as young as 2 to 3 years of age are sensitive to variable rules and constraints (Docherty, Foukes, Tillotson, \& Watt, 2006). Thus, the optionality or variability of certain segments and structures in AAE (to be described below) may be expected to lead to differences in the developmental timetables for AAE and MAE learners (Roberts, 1997, 2006)

Salient dialect features that are contrastive (i.e., different in the two dialects), which may therefore interact with developmental trajectories, are described in the following paragraphs.

Phonetic segments. Segmental differences between AAE and MAE are relatively few, but often the same segments are realized differently in the two dialects. For example, in AAE adult language, MAE segments $/ \delta /$ and $/ \theta /$ tend to be replaced by alveolar stops in initial position and by either labial fricatives or alveolar stops in

AQ4 medial and final contexts (Bailey \& Thomas, 1998; Pollock et al., 1998; Rickford, 1999; Stockman, 1996). Thus, AAE-learning children hear relatively few tokens of interdental fricative segments. Furthermore, final stops and fricatives are often devoiced in $\mathrm{AAE}$ adult language, and final $/ \mathrm{d} /$ is often replaced by a glottal stop (Bailey \& Thomas, 1998; Fasold, 1981; Wolfram, 1994).

Vocalization or absence of liquids is also more typical of AAE than MAE (Bailey \& Thomas, 1998; Hinton \& Pollock, 2000; Pollock \& Berni 1996, 1997; Rickford, 1999; Wolfram, 1994). The liquid / 1 is vocalized or deleted, especially in final position and before labials, as in hep for help (Bailey \& Thomas, 1998; Pollock et al, 1998; Rickford, 1999). The segment $/ \mathrm{r} /$ is often absent intersyllabically, in syllabic contexts, postvocalically, and in clusters (specifically after $/ \theta$ / and in unstressed syllables), whereas some speakers of AAE have been observed to hyperarticulate postvocalic /r/ (Pollock \& Berni, 1996, 1997). These predictable changes, therefore, may indicate to the AAE learner that variations in the manner of production of core consonants are required in many contexts

AQ5 Phonotactic structures. Although several segmental differences have been noted, the most salient differences between AAE and MAE are phonotactic-that is, differences of syllable and word structure. Coda (word or syllable final consonant) constraints result in the frequent absence of final stops and nasals in AAE. This absence is generally considered a zero realization of the underlying consonant (i.e., a phoneme from the underlying representation that is not overtly manifested in some cases). The presence of these consonants in speakers' lexical representations is demonstrated by compensatory vowel nasalization before target nasals and vowel lengthening before target voiced consonants (Moran, 1993; Stockman \& Vaughn-Cooke, 1989). Also, coda consonants are more often pronounced when they occur before pauses or "onsetless" wordsthose that begin with vowels (Stockman, 1996; Wolfram, 1991). Thus, for example, the final [k] in book might be produced in the phrase book of poetry but would be likely to be zero-realized in the phrase book prize

Similarly, final consonant clusters are often reduced or omitted in AAE. In principle, all final segments and clusters are considered contrastive, as the environment for the phonological rule in MAE that deletes a consonant when there are three consonants in a row applies in AAE when there are two consonants together (Bailey \& Thomas, 1998; Rickford, 1999). Thus, final consonants and clusters are present much less often in spoken AAE than in spoken MAE Again, preservation is variable and is more likely before onsetless words, indicating that these final clusters are included in the speakers' underlying representations of words even when they are not pronounced (Bailey \& Thomas, 1998; Laing, 2003; Rickford, 1999). In addition to the phonological patterns described above, in AAE, various coda morphemes $(/-\mathrm{t} /, /-\mathrm{d} /, /-\mathrm{s} /, /-\mathrm{z} /)$ are omitted for grammatical reasons at different rates. For example, although they are identical phonologically, in that both may result in a final cluster, plural /s/ is more likely to be retained than third person singular $/ \mathrm{s} /$. This is yet another factor leading to fewer codas in the target AAE dialect.

For the most part, initial clusters and the initial position of the word in general are not different in AAE versus MAE. In adult $A A E$, word-initial clusters are reduced or substituted only in very specific circumstances, such as in clusters with target $/ \mathrm{r} /$ and $/ \mathrm{j} /(\mathrm{e} . \mathrm{g}$, /kjut/ $\rightarrow$ [krut]; Bailey \& Thomas, 1998; Rickford, 1999; Wolfram, 1994). One notable exception is the initial cluster /str-/, which may be realized as [skr-] in some regions, although the $/ \mathrm{r} /$ itself may be unchanged in that environment (Bailey \& Thomas, 1998; Pollock et al, 1998; Rickford, 1999).

As in MAE, AAE speakers show a preference for trochaic words (i.e., a stressed syllable followed by an unstressed syllable), but in AAE, there is even more deletion of initial weak syllables from iambic words and of medial weak syllables, particularly in reduplicated contexts (e.g., Mississippi $\rightarrow$ Missippi) (Bailey \& Thomas, 1998; Rickford, 1999; Vaughn-Cook, 1987). Stress shift onto initial weak syllables (trochaicization; e.g., UMbrella or POlice) is also observed in AAE

Another salient difference between AAE and MAE results from movement rather than omission of elements; that is, a salient feature of AAE is the metathesis of $/ \mathrm{s} /+$ stop, as in certain words such as ask (realized as [æks]). This may be mostly lexically specified (Bailey \& Thomas, 1998; Rickford, 1999) and not a widespread pattern, but because a word like ask is so commonly used, this pronunciation is often noted even by naive listeners.

Thus, there are many observable aspects of differences between the phonologies of AAE and MAE that may be expected to interact with typical child patterns to create differences in the timetables for phonological acquisition among second-dialect speakers of MAE.

\section{Previous Studies of Child AAE Phonology}

Contrastive elements. Craig and Washington and their colleagues have published several normative studies involving cohorts 


\section{LSH4003_Pearson (1st Proof)}

of AA children in cross-sectional groups They established that almost all AA children entering public school in Detroit, $\mathrm{MI}$ and recruited for their studies were speakers of AAE (100\% in Craig \& Washington, 2002; 94\% in Craig et al, 2003), and further, that more students exhibited phonological dialect features than morphosyntactic ones (Craig et al., 2003, 2004). Even middle-class AA children, who may be expected to have more opportunity to learn mainstream dialects, retain many aspects of AAE in their speech (Horton-Ikard \& Miller, 2004).

Craig and Washington (2004) explored a set of contrastive AAE dialect elements and confirmed that substitutions for $/ \partial /$ and $/ \theta /$, consonant cluster reduction, and final consonant deletion were among the most common patterns demonstrated by the AAE speakers, followed by consonant cluster movement, weak syllable deletion, fronting of $/ \mathrm{y} /$ to $[\mathrm{n}]$, and syllable addition. Although there was a significant reduction at first grade in the number of dialect features produced, approximately $50 \%$ of the children through fifth grade (the oldest children in their study) persisted in using some AAE phonological dialect features. Thirty-seven percent of the Michigan second through fifth graders in their study reduced consonant clusters, $57 \%$ monophthongized diphthongs, and $45 \%$ substituted other phones for interdental fricatives. Craig and Washington's descriptions of phonological features do not include prekindergarten or kindergarten participants as they maintain that, "at this time in a child's development it is difficult to determine whether phonological variations reflect dialectal features or motor immaturity" (i. e., development; Craig \& Washington, 2004, p 45.3) Thus, the developmental status of even contrastive features of $\mathrm{AAE}$ at those ages is not clear:

With respect to consonant production, Seymour and Seymour (1981) found that 4- and 5-yeat-old northeastern children learning AAE omitted word-final stops more frequently than did MAE speakers According to Seymour and Seymour, 34\% of AAE children's phonological mismatches to MAE targets were in initial position; $32.5 \%$ in final. In contrast, $35 \%$ of MAE speakers' mismatches were in initial position, but only $21.5 \%$ in final Interestingly, these AAE-learning children acquired prevocalic singleton $/ \mathrm{r} /$ ahead of children learning only MAE, and they had fewer substitutions for it in initial position.

Also, weak syllable deletion may be more common in AAE than MAE learners. The persistence of such deletions has been identified as a "red flag" for phonological delay or disorder in MAE (Velleman \& Shriberg, 1999). However, these patterns may be more typical in AAE As discussed above, stress shifts and absence of weak syllables in initial position result in decreased frequencies of iambic words in adult AAE (Stockman, 1996; Wolfram, 1994) Craig et al. (2003) reported that between $5 \%$ and $10 \%$ of their school-age participants exhibited weak syllable deletion. Children who have been exposed to AAE may be expected to demonstrate more frequent stress shifts/trochaicization and more persistent and pervasive patterns of weak syllable omission in words that are pronounced iambically

Noncontrastive elements. Almost no studies have focused on similarities in the development of the elements that do not contrast, or differ, across dialects. One exception is the suggestion from Seymour and Seymour (1981) and Stockman (2006) that prevocalic $/ \mathrm{r} /$ typically develops in AAE on a similar timetable or perhaps a little in advance of its development in the MAE learners they observed. Seymour, Roeper, and de Villiers $(2003,2005)$ explored patterns of dialect similarities as well as differences in acquisition, and they incorporated principles based on Seymour and Seymour's (1977) contrastive/noncontrastive model into the Dialect Sensitive Language Test (DSLT; Seymour, Roeper, \& de Villiers, 2000), the more extensive, unpublished pilot edition of the Diagnostic Evaluation of Language Variation (DELV; Seymour et al., 2003, 2005). For example, they determined that substitution of labiodental fricatives for interdental fricatives (like [maf] for moth) were among the most contrastive features between the dialects and are thus suitable for dialect identification through age 12 (Seymour et al., 2003). Likewise, the DSLT authors restricted their phonological diagnosis of disordered versus typical phonological development to initial position where the specific clusters tested were noncontrastive between the two dialects (Seymour, 2004; Seymour et al., 2005). The rationale for the selection of items has been discussed by Seymour (2004), but analyses of the pilot data used have not appeared in published form before now.

\section{Hypotheses}

Previous studies provide limited support for both similarities and differences between $\mathrm{AAE}$ and MAE. Based on the similarities and differences between $\mathrm{AAE}$ and MAE speakers of MAE noted above, we hypothesize the following:

Hypothesis $1(\mathrm{H1})$. AA children acquiring MAE as a second dialect will be equivalent to MAE speakers in their accuracy of consonant production in initial position. Age of mastery, segment by segment (and cluster by cluster), will show few differences in initial position.

$\mathrm{H} 2$. $/ \mathrm{r} /$ may develop somewhat precociously in initial position in AAE-learning children. This will be seen in clusters with / $\mathbf{r}$ / as well.

H3. Almost all segments and clusters will develop later in final position in AAE learners of MAE than MAE learners. Age of mastery by specific segment and cluster will differ by dialect.

H4. The asymmetry between initial and final position that has been observed in AAE learners of MAE will be observed among MAE children for only a few phones.

H5. Interdental fricatives, especially the voiced segment $/ \mathrm{d} /$, will show less asymmetry; that is, they will differ across dialects in both initial and final position.

H6. Initial weak syllables will have a greater effect on AAE learners of MAE than on MAE learnets. That is, relative to the same segment in a stressed syllable, AAE learners of MAE will produce a consonant in an initial weak syllable less accurately than will MAE learners

H7. Dialectal differences will be greater at later ages, but nonetheless will be discernable at age 4 despite convergence with developmental patterns

\section{METHOD}

\section{Participants}

Participants were the 854 typically developing children ages $4 ; 0$ (years;months) to $12 ; 11$ who took the DSLT as part of the preliminary fieldtesting for the DELV. Children were recruited 


\section{LSH4003_Pearson (1st Proof)}

from two language communities, $\mathrm{AAE}$ and MAE. At the time of recruitment, parents and teachers filled out a dialect usage and language background questionnaire. Criteria for membership in the AAE group were (a) AA background (by parent self-report) and (b) residence in a community of predominantly AAs (by census report; U.S. Bureau of the Census, 2000), as well as (c) reported usage of AAE according to participating SLPs. Criteria for membership in the MAE group were (a) predominantly European American background (by parent and examiner report) and (b) residence in a community that did not have a predominance of $\mathrm{AA}$

FN1 residents. ${ }^{1}$

It would be essentially impossible to locate participants with exposure to only AAE, as young AAE learners are highly likely to have exposure to MAE via media sources if not in personal interactions. However, as shown by Craig and Washington.(2002) and Horton-Ikard and Miller (2004), AAE is the primary dialect of first exposure for most AA children when they enter school, even those with middle-class backgrounds (Horton-Ikard \& Miller, 2004). The participants' status as typically developing and not language impaired or phonologically impaired was determined by clinician judgment within their educational settings. No children in this sample had been referred for intervention in their school or community setting, nor were any of them receiving speech or language services. They were approximately evenly divided between males and females, with slightly more females in both groups.

The parent education level of $77 \%$ of the sample, including both ethnic groups, was high school or lower; only 3\% had finished college. These lower parent education levels were especially recruited because those homes are thought to have higher levels of AAE usage (Craig, Washington \& Thompson-Porter, 1998; Linnes, 1998; Stockman, 1996). For the same reason, more Southerners than Northerners were recruited. Participants came from all over the United States, in proportions that approximate the regional distribution of the AA population in the 2000 U.S. Census report, with the following exceptions: South $(60 \%$, instead of $51 \%$ as in the census), North Central (25\%), Northeast ( $6 \%$ instead of $16 \%$ ), and West $(9 \%)$.

AQ6 Region, parent education level, and gender were included as control variables in the analyses of variance (ANOVAs) of the major dependent variables, age and dialect. These participant characteristics are summarized in Table 1.

\section{Materials}

A preliminary, more extensive, version of the DELV, the DSLT, was used as a measure in this study. It consists of a stimulus book with 350 items distributed across 14 subtests, including some that are designed to be contrastive between the dialects and the remainder that are designed to be noncontrastive. The phonology portion of the instrument consists of 66 items with 132 target segments. The items for the current study consisted of all 110 DSLT tokens in initial or final position (as opposed to medial position), testing segments and clusters of the 74 types noted in

TBL2 Table 2. Fifty-five targets were contrastive (all final consonants plus initial $/ / /$ ) and 55 were noncontrastive Like many phonology

\footnotetext{
${ }^{1}$ Thirty-one of the $317 \mathrm{MAE}$ participants reported $\mathrm{AA}$ ethnicity, and 61 reported Hispanic ethnicity, but parents reported speaking only English in the home.
}

assessment instruments (Velleman, 1998), the focus was on consonants only."

Colorful picture stimuli were described by the examiner using preset sentences; the children were told to repeat the sentences verbatim. According to Seymour (2004), the difficulty level was increased by embedding the target words in the sentences (e.g., I see the boy close the door), by including multisyllabic as well as monosyllabic words, and by including three- as well as twoelement clusters. Multisyllabic targets included both iambic and trochaic words. For clusters, the DSLT selected just those that were thought to be the most and the least contrastive between the dialects (Seymour, 2004). Thus, the stimuli included an overselection of liquid clusters because there have been several suggestions that they might be less contrastive than other phonemes (Seymour \& Seymour, 1981; Stockman, 2006). In the interest of space, many of the more contrastive cluster stimuli were not included in the DSLT (Seymour, 2004).

To the extent permitted by MAE phonotactics, all consonant segments and many consonant clusters were tested in both initial and final position (except initial / $\mathrm{p}$ /, which was omitted by oversight) A possible confound existed because some final consonants and clusters were tested in prevocalic position, some in preconsonantal position, and some phrase- or sentence-finally, depending on whether the test item was intended to be contrastive or noncontrastive (That is, an item to be used to identify an AAE speaker would more likely use a preconsonantal context, whereas for noncontrastive items, facilitating prevocalic or sentence-final contexts were used). Because several consonants that occurred preconsonantally also occurred prepausally or prevocalically, the effect of the following phone could be examined to verify that it did not systematically distort the results. Actual targets tested in the DSLT (a superset of those tested in the DELV) and their contexts are provided in the Appendix

\section{Procedure}

Children were tested individually in a quiet room at their schools by certified SLPs. More than 400 SLPs participated. They were supervised by the DSLT Project Director at The Psychological Corporation, who is herself an SLP. In particular, examiners were not permitted to continue testing until they participated in a follow-up discussion of their first case with project staff If any irregularities were noted, that case was not counted and a second case was submitted to the same scrutiny. Younger children were typically tested in at least two sessions. The order of administration was consistent across all participants, with the phonology items given next to last.

To explore the potential effect of examiner ethnicity on the outcomes, 12 of the AA children, ages 4,5 , and 6 years, were tested by AA examiners, and their results were compared to a set of children matched on age, ethnicity, gender, region, and parent education level who were tested by Caucasian examiners.

Examiners recorded children's productions of the target stimuli by hand on preprinted sheets. The SLPs' records were entered into a spreadsheet that recorded whether the child's response matched its target or not, and if it did not match, there was a notation of what the child's actual response was relative to the target. The examiners marked the record forms in the international phonetic alphabet,

\footnotetext{
${ }^{2}$ The status of $/ \mathrm{r} /$ in postvocalic preconsonantal position is debated Given its assumed status as a cluster member on most articulation tests in the field, we treat it as such here
} 
Table 1. Participant characteristics by age and gender.

\begin{tabular}{|c|c|c|c|c|c|c|c|c|}
\hline & \multicolumn{6}{|c|}{ Age (years, months) } & \multirow[b]{2}{*}{ Total } & \multirow[b]{2}{*}{$\%$} \\
\hline & $4,0-4 ; 11$ & $5 ; 0-5 ; 11$ & $6,0-6 ; 11$ & $7,0-8,11$ & $9,0-10 ; 11$ & $11,0-12,11$ & & \\
\hline \multicolumn{9}{|l|}{$\mathrm{AAE}$} \\
\hline Parent education & 2.9 & 3.1 & 2.9 & 30 & 3.1 & 3.1 & 30 & \\
\hline $\mathrm{F}$ & 58 & 68 & 84 & 24 & 31 & 22 & 286 & 53 \\
\hline$M$ & 51 & 61 & 58 & 24 & 33 & 24 & 251 & 47 \\
\hline All & 109 & 129 & 142 & 47 & 64 & 46 & 537 & \\
\hline \multicolumn{9}{|l|}{ MAE } \\
\hline Parent education & 3.2 & 30 & 2.9 & 3.4 & 33 & 33 & 32 & \\
\hline $\mathrm{F}$ & 32 & 35 & 47 & 20 & 22 & 26 & 182 & 57 \\
\hline $\mathrm{M}$ & 28 & 25 & 26 & 14 & 19 & 23 & 135 & 43 \\
\hline All & 60 & 60 & 73 & 34 & 41 & 49 & 317 & \\
\hline Total & 169 & 189 & 215 & 81 & 105 & 95 & 854 & \\
\hline
\end{tabular}

Note. $\mathrm{AAE}=$ speaker of African American English as a first dialect, $\mathrm{MAE}=$ speaker of Mainstream American English Average parent education level: On a 5-point scale (adapted from The Psychological Corporation), 1 represents no complete years of high school, 3 represents a high school degree, and 5 represents a college degree. An additional 400 children with language impairments participated in the fieldtesting, but their results are not reported here.

but their entries were represented in standard orthography in our database (e.g., "controw' for control pronounced without the final $/ 1 /$; and '?' representing a distortion, as in 'denti??' for dentist with a distortion in both elements of the final cluster).

To ensure that the database of results faithfully represented the information on the record forms, 31 record forms were handscored by the fourth author. In fact, no discrepancies were found between the handwritten data and the data that were entered in the computer. For the most part, the research group did not have access to audiotapes of the children's responses for purposes of reliability, but 60 examiners had made audiotapes of selected sections of the test. The tapes were intended as a check to see that the examiners were following the standardized directions, but they also provided a record of the children and how their performances were interpreted by the examiners. Fifty-five of the tapes included narrative samples, which were transcribed and used to confirm the examiners' online scoring of the narrative elements. The scoring done from the transcripts was shown to have $89 \%$ agreement with the examiners' online scoring (de Villiers, Burns, \& Pearson, 2005). Two tapes included the phonology subtest. Like the narrative tapes, the phonology tapes gave no cause for concern. They were scored independently by the second author; who is a linguist and a certified SLP. Her transcriptions of the 410 targets (132 items of which 57 were two-place clusters and 8 were three-place clusters, or 205 targets for each child) showed

Table 2. Targets by type and position.

\begin{tabular}{|c|c|c|c|c|c|c|}
\hline & \multicolumn{2}{|c|}{ Singleton } & \multicolumn{2}{|c|}{ Cluster } & \multicolumn{2}{|c|}{ All } \\
\hline & Type & Token & Type & Token & Type & Token \\
\hline Initial & 21 & 31 & 19 & 25 & 40 & 56 \\
\hline Final & 19 & 35 & 15 & 19 & 34 & 54 \\
\hline All & 40 & 66 & 34 & 44 & 74 & 110 \\
\hline
\end{tabular}

94\% agreement with the examiners' notations overall. As expected, reliability was slightly higher $(96 \%)$ for the child with primarily AAE mismatches (21/30) and slightly lower (92\%) for the child with a higher number of both contrastive and noncontrastive mismatches (that is, 29 contrastive and 31 noncontrastive). Further consideration of reliability is found in the Discussion under Limitations of the Study.

It should be noted that "match to MAE target" is a descriptive criterion, not a normative one. The goal of the fieldtesting was to find areas where the two developing dialects differed and where they were the same. The contrastive elements and contexts were selected to verify that the productions of the children who were learning AAE would not match the targets, as hypothesized. However, for almost all of the children, the model produced by the examiner, as in I see a bird taking a bath, was spoken in its MAE citation form, and the MAE form was taken as the reference point.

\section{Coding}

Each response was coded as to whether it matched the MAE target $(1=$ match; $0=$ other $)$. Each other was further coded for whether it was an omission, substitution, or distortion Codes for each target consonant and cluster in each position were tallied by dialect group and age. For the milestones, a segment was counted as reaching "MAE mastery" for a dialect group at the age when the percentage of MAE responses for that group reached $90 \%$ (a standard adopted from Brown, 1973).

In addition, several summary variables were created in order to compare dialect groups by age for the specific categories (i.e., initial singletons, final clusters, all initial elements, all final elements) and for the relationship between initial and final elements. For the summary variables, the items in each category were simply totaled. Although this gives more weight to segments with more targets (e g., there were two initial /g/ targets, but only one initial /f/), each participant and each group had the same items in the same proportions, so no correction was deemed necessary. Several analyses were redone without the interdental fricatives. The 


\section{LSH4003_Pearson (1st Proof)}

relationship between initial and final elements was compared with a repeated measures ANOVA, with age and dialect group as the between-subjects variables.

In order to confirm that the variance that was attributed to age and dialect did not derive from one of the control variables, the ANOVAs were done with region, gender, and parent education level in addition to the relevant factors of age and dialect. (Parent education level was entered in a separate ANOVA because its five levels, in conjunction with six ages, two dialect groups, four regions, and two genders, exceeded the power of even the large number of participants in this study. With $5 \times 6 \times 2 \times 4 \times 2$, or 480 combinations, there were too many empty cells.) Because five independent ANOVAs were done, a Bonfertoni correction was applied to guard against Type 1 error. Thus, the alpha value for $p$ was $01(.05 / 5)$.

\section{RESULTS}

\section{H1 to H3: Developmental Milestones}

TBL3 Table 3 presents findings to address the following issues relevant to Hypotheses 1 through 3 , focusing on ages of mastery (90\% match to MAE target) of singletons and clusters in initial versus final position for children from the two dialect groups.

Order of acquisition for singletons. As noted earlier, studies of the adult dialects would lead one to expect that initial position should be noncontrastive overall, with the exception of the interdental fricatives. One might also see, as some studies of AAE phonological development have suggested, that despite omissions of postvocalic $/ \mathrm{r} /$ in some varieties of AAE, prevocalic $/ \mathrm{r} /$ may be acquired earlier by AAE speakers than by MAE speakers

Singleton consonants in initial position. For most "early 8 " and "middle 8 " (Shriberg, 199.3) segments $(/ \mathrm{b} /, / \mathrm{t} /, / \mathrm{d} /, / \mathrm{k} /, / \mathrm{g} /, / \mathrm{m} /, / \mathrm{n} /$, $/ \mathrm{h} /, / \mathrm{j} /, / \mathrm{w} /, / \mathrm{f} /, / \mathrm{d} z /, / \mathrm{t} / /)$ and two "late 8 " segments $(/ \mathrm{S} /, / \mathrm{l} /)$ in initial position, both groups were at ceiling at age 4 years, the initial data point in the study. Comparisons of order of acquisition can be made only for later acquired phones, as shown in columns 1 and 2 of Table 3. Some relatively later developing initial segments (cf. Smit et al; 1990; Shriberg, 1993) were produced in the MAE manner at age $5(/ \mathrm{v} /, / \mathrm{z} /)$ and age $6(/ \theta /)$ by both groups. Notably, two late 8 (Shriberg, 1993) initial consonants, $/ \mathrm{r} /$ and $/ \mathrm{s} /$, were acquired 2 years earlier by the AAE group than the MAE group. In comparison, the other interdental fricative, $/ \mathrm{O} /$, did not reach the $90 \%$ criterion by age 12 years among the AAE group, even in this noncontrastive position.

Singleton consonants in final position. By contrast, in final position, MAE learners across the age range had a greater proportion overall of matches to the adult MAE targets, as depicted in columns 6 and 7 of Table 3. Fifteen singleton phones in final position were reported to be at the $90 \%$ level for MAE learners between $4 ; 0$ and $4 ; 11$, the youngest age group in the study. As noted in Table 3 , only $/ \mathrm{s} /, / \mathrm{z} /, / \theta /$, and $/ \mathrm{\delta} /$ were acquired after age 4 by the MAE dialect group. For AAE learners, nine segments were fully AQ8 at the criterion at age 4 ; two of them, final $/ z /$ and final $/ \mathrm{s} /$, were acquired earlier by the AAE group than the MAE group. However, in this position, neither $/ \mathrm{O} /$ nor $/ \theta /$ reached the $90 \%$ criterion for the AAE speakers by $12 ; 0-12 ; 11$, the oldest age group in the study

With respect to the question of whether velars, nasals, fricatives, and affricates tend to be mastered in final position before initial position, our results were mixed. The AAE group mastered $/ \mathrm{s} /$ in final position before initial; the MAE learners similarly acquired $/ \mathrm{v} /$ finally before initially. All other velars and fricatives were acquired in initial position first by children from both groups.

Order of acquisition for consonant clusters. In cluster acquisition, a similar picture emerged: As illustrated in columns 3, 4,8 , and 9 of Table 3 , the dialects were largely noncontrastive for clusters in initial position, and very contrastive in final position. AAE learners reached criterion for many initial clusters slightly

Table 3. Developmental milestones for MAE consonants, by dialect

\begin{tabular}{|c|c|c|c|c|c|c|c|c|}
\hline \multicolumn{2}{|c|}{ Initial singleton } & \multicolumn{2}{|c|}{ Initial cluster } & \multirow{2}{*}{$\begin{array}{l}\text { Age of } \\
\text { mastery } \\
\text { (by year) }\end{array}$} & \multicolumn{2}{|c|}{ Final singleton } & \multicolumn{2}{|c|}{ Final cluster } \\
\hline$A A E$ & $M A E$ & $A A E$ & $M A E$ & & $A A E$ & $M A E$ & $A A E$ & $M A E$ \\
\hline \multicolumn{2}{|c|}{$\begin{array}{l}(\mathrm{p})^{\mathrm{a}}, \mathrm{b}, \mathrm{t}, \mathrm{d}, \mathrm{k} \\
\mathrm{g}, \mathrm{w}, \mathrm{j}, \mathrm{m}, \mathrm{n} \\
\quad \mathrm{f}, \mathrm{h}, \mathrm{f}, \mathrm{t} f, \mathrm{~d}, \mathrm{~d}, \mathrm{l}\end{array}$} & $\mathbf{k l}, \mathbf{p l}, \mathbf{k r}$ & $\mathbf{t r}$ & 4 & \multicolumn{2}{|c|}{$\left.\mathrm{m}, \mathrm{n}, \mathrm{p}, \mathfrak{\mathrm { y }}, \mathrm{f}, \int, \mathrm{t}\right\}, \mathrm{r}$} & \multicolumn{2}{|c|}{$\mathrm{mp}$} \\
\hline $\mathbf{r}, \mathbf{s}$ & & & & & $\mathbf{s}, \mathbf{z}$ & $\begin{array}{l}\mathbf{b}, \mathbf{t}, \mathbf{d}, \mathbf{k}, \mathbf{g} \\
\mathbf{v}, \mathbf{d}, \mathbf{3}, \mathbf{l}\end{array}$ & & $\begin{array}{l}\text { nt, } \mathbf{k}, \text { ld, lt } \\
\text { ks, rl, rf }\end{array}$ \\
\hline \multicolumn{2}{|c|}{$\mathrm{v}, \mathrm{z}$} & $\mathbf{p r}, \underset{t r}{\mathrm{gr}}, \mathbf{s p}, \mathbf{s t}$ & $k l, p l$ & 5 & $b, d_{3}, l$ & & $\begin{array}{c}\mathbf{r s} \\
\eta k, k s, r l\end{array}$ & rd \\
\hline & & & & 6 & $k, g, v$ & s, $z$ & if & $\underset{r s}{\mathbf{f t}, \mathbf{s k}, \mathbf{r t}}$ \\
\hline & $\begin{array}{c}r, s \\
0\end{array}$ & skr & $\begin{array}{c}p r, k r, g r, s p, s t \\
\text { str, } \int \mathbf{\int}, \theta \mathbf{\theta r} \\
s k r\end{array}$ & 8 & $t, d$ & & $n t, r d$ & st \\
\hline$\partial$ & & $\begin{array}{c}\theta r \\
\int r, s t r\end{array}$ & & $\begin{array}{l}10 \\
12+\end{array}$ & $\theta, \partial$ & $\theta$, & $\begin{array}{c}l d, r t \\
l t, f t, s k, s t, r \theta\end{array}$ & $r \theta$ \\
\hline
\end{tabular}

Note. Bold $=90 \%$ criterion reached earlier in that dialect, Italic $=90 \%$ criterion reached later in that dialect, Neither bold nor italic $=90 \%$ criterion reached at the same time in both dialects (noncontrastive).

${ }^{2}$ Initial singleton /p/ was omitted by oversight. We place it in the 4-year-old box following the Smit et al. (1990) guideline for its acquisition Initial $/ \mathrm{p} /$ is included in the initial clusters $/ \mathrm{pr} /, / \mathrm{pl} /$, and $/ \mathrm{sp} /$. 


\section{LSH4003_Pearson (1st Proof)}

earlier than MAE learners. By contrast, there were more contrastive (final) clusters at the $90 \%$ criterion earlier for MAE learners.

Initial clusters. The AAE advantage with initial singleton $/ \mathrm{r} /$ conferred an advantage with several initial clusters with $/ \mathrm{r} /$, but several other clusters were contrastive in the opposite direction (MAE earlier than AAE) in initial position as well, not surprisingly including those with the interdental fricative $/ \theta /$. In addition, there were differences in the initial /str-/ in street and / $/ \mathrm{r}-$ / in shrimp, both of which are sometimes pronounced in $\mathrm{AAE}$ as [skr-]. Note that initial $/ \mathrm{S} /, / \mathrm{st}-/$, and $/ \mathrm{tr}-/$ were all at criterion by age $5 ; 11$ for the AAE learners, so the segments themselves do not appear problematic Nor were three-place clusters more difficult for AAE learners than MAE learners, as demonstrated by /spl-/ and /skr-/, which were also at criterion at the same age or earlier for AAE speakers. We conclude, therefore, as suggested by Bailey and Thomas (1998), Rickford (1999), and Green (2002), that these substitutions are not a response to a phonological or motoric limitation, but show that the children had acquired that element of the dialect.

Final clusters. In final position, the clusters tested reached the $90 \%$ criterion according to the timetable shown in columns 8 and 9 of Table 3. MAE participants had reached the $90 \%$ criterion for eight of the final clusters tested by age 4, but only one initial cluster AAE speakers had reached criterion for only one final cluster by age 4 , but three initial clusters, confirming that final position is strongly disfavored in this dialect group. Two final clusters emerged as noncontrastive, and contrary to our predictions about final clusters, /-rs/ was at criterion slightly earlier in AAE, age 5, versus age 6 for the MAE group. Two of the five earliest final clusters for AAE speakers were homorganic $(/-\mathrm{mp} /, /-\mathrm{n} \mathrm{k} /)$, but the other three contained the later developing phones for which they demonstrated an advantage in singletons (/-rs, $-\mathrm{rl},-\mathrm{ks} /)$

Test for ethnicity of the examiner. In the comparison of AA children who were tested by an AA or an MAE examiner, mean number of "matches to MAE" was the dependent variable. For the noncontrastive (initial) items, the mean match scores were the same regardless of the ethnicity of the examiner (mean with AA examiner $=53.4$ vs mean with Caucasian examiner $=52.3, F(1,22)=$ $.386, \mathrm{n} \mathrm{s} ., \eta^{2}=.017$ ). In the contrastive (final) position, match scores of AA children tested by the Caucasian examiners $(M=47.7$ of 54) were higher than the match scores of those tested by the AA examiners $(M=41.4)$. The difference is statistically significant, $F(1,22)=5.285, p=03, \eta^{2}={ }_{1} 194$, indicating that the children were more likely to use AAE targets with AA examiners. Thus, the differences between the $\mathrm{AAE}$ and MAE groups reported in this article for the contrastive items are most likely smaller than what might have been found if there had been more AA examiners However, the match scores for noncontrastive items, on which the proposed diagnostic milestones are based, do not appear to be affected by the ethnicity of the examiner

Test of the effect of the following phone on the results. The results of statistical tests of the effect of the following context are reported in the superscripts and notes for Tables 1 and 2 in the Appendix. Although differences in the expected direction were statistically significant by chi-square test in a few of the cases, following phone was not a consistent effect. The chi-square test was significant for 7 of the 14 comparisons, and in 4 cases, the test was significant in the opposite direction. Alternate explanations were the occurrence of a phoneme in an unstressed syllable or in unfamiliar words. For example, both toast and dentist were followed by a consonant, but the /st/ was more likely to be pronounced in the single stressed toast than in the unstressed final syllable of dentist. Another pair that went against expectation was drive followed by a consonant, which was easier than stove at the end of a phrase. In this case, it appears that the familiarity of the word (drive vs. stove) played a larger role than pure phonology in the retention of the final consonant. Although following phone seemed to have some effect on the outcomes, it appears not to be a dominant factor in the results.

\section{H4. Testing the Asymmetry Between Initial and Final Position}

Figures 1 and 2 show that AAE and MAE children's scores were indeed equivalent for phones in initial position but not final position. This is seen for all ages combined in Figure 1 and broken out by ages in Figure 2. The global asymmetry by position is demonstrated in Table 4, which gives the means and standard deviations for the composite scores and their subcomponents in initial and final position. The mean difference between groups for initial position was less than 0.7 , which is a tiny fraction of the pooled standard deviation of 4.8 , whereas in final position, the mean difference was approximately three quarters of the pooled standard deviation of 6.4 . In initial position, when the item with $/ \mathrm{d} /$ was removed from the score, the means for the two dialect groups were even closer. In final position, even without the four items with interdental fricatives, the MAE mean was still higher by more than half of the pooled standard deviation of 2

When scores were converted to $z$ scores, the distribution of initial scores relative to the total group mean was very similar: The percentage of scores that were $1 S D$ below the mean was approximately $12 \%$ in both groups. By contrast, in final position, many more AA children than MAE children were $1 S D$ below the group mean: AAE, 107 of 537 children, or $20 \%$, versus MAE, 16 of 317 children, or $5 \%$, which is a significant difference, $\chi^{2}(1, N=854)=21.09, p<0005$. For $2 S D$ s below the group mean, the difference is also significant: AAE, 42 of 537 , or $7.8 \%$, versus MAE, 2 of 317 , or $0.6 \%, \chi^{2}(1, N=854)=35.79, p<0005$.

The greater differences in final position are explored first.

Elements in final position. As seen in columns 6 through 9 of Table 3, there was an earlier timetable for MAE children to match the final targets almost across the board. In the ANOVA reported in

Figure 1. Effect of initial versus final position (singletons and clusters) by dialect.

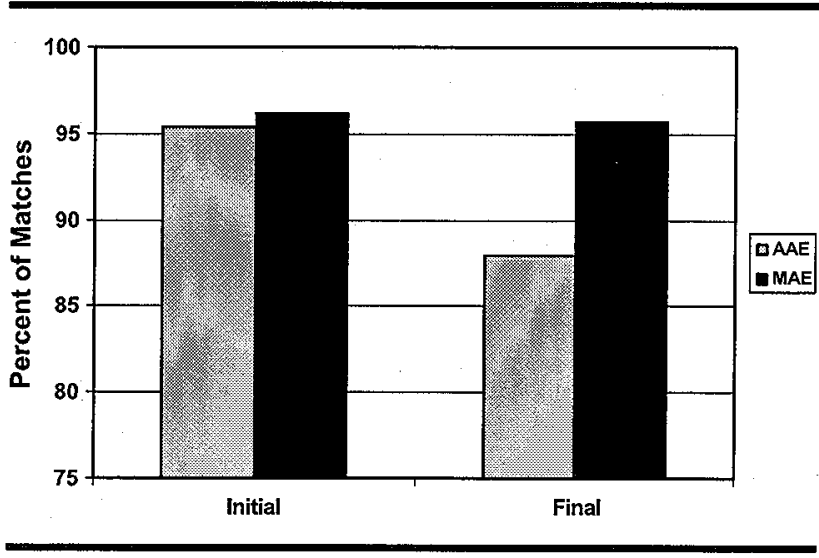


Figure 2. Initial and final consonant clusters compared by age and dialect.
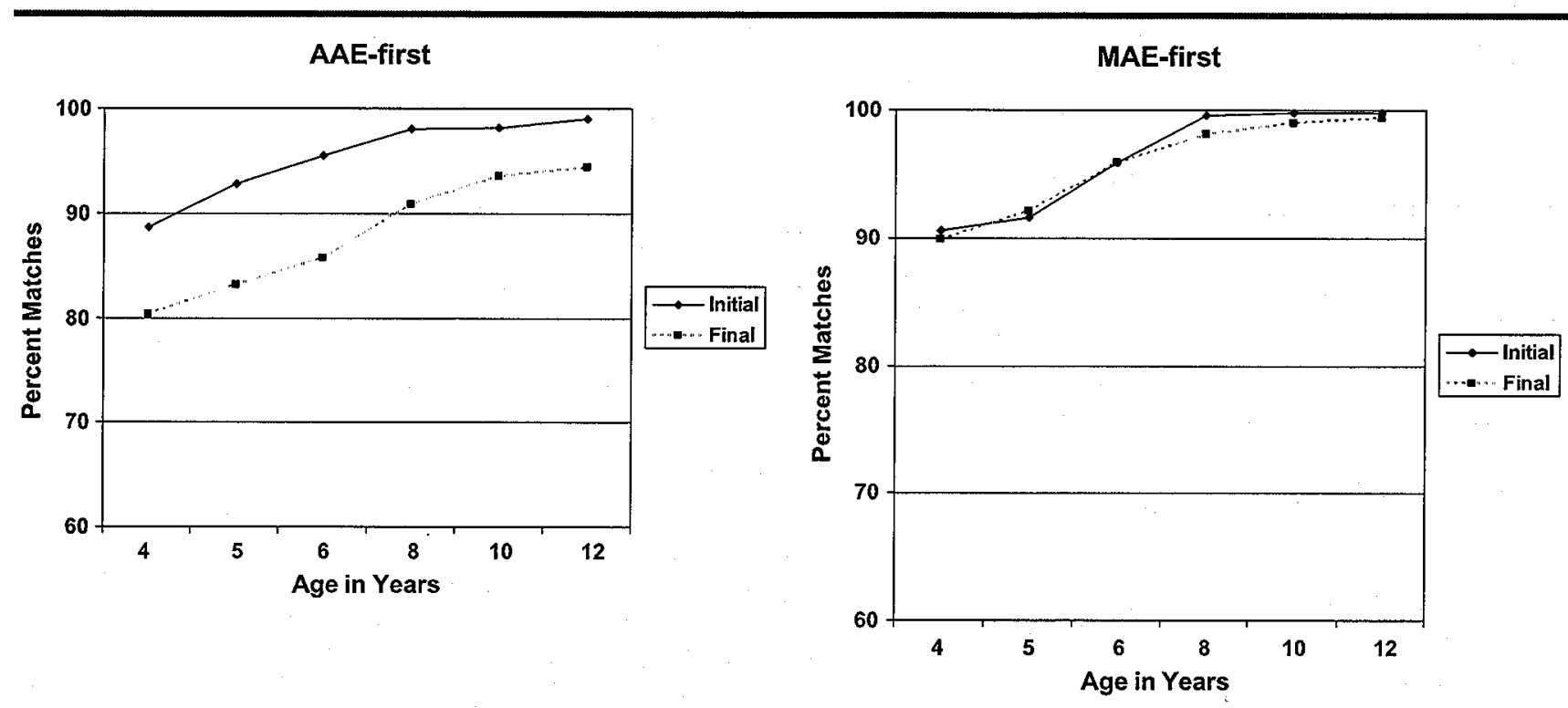

TBL5 Table 5, age and dialect were significant main effects. Region, gender, and parent education were not significant, and there were no significant interactions.

Final singletons and clusters. The mean differences between dialect groups for final clusters and singletons are also shown in Table 4. As shown in Table 5, both age and dialect group are significant factors, but none of the control variables reach significance for these dependent variables.

Elements in initial position. In initial position, age was the only significant factor for differences in MAE-like production in the ANOVA Among the variables dialect, region, gender, parent education level, and their various interactions, none was significant

TBL6 (see Table 6).

Because our hypothesis with respect to initial segments predicted that there would be "no difference" between the groups, avoiding Type 2 error was more crucial than avoiding Type 1 error: Therefore, Bonferroni correction was not used in this case

Initial singletons and clusters. The effects were similar for initial singleton consonants and initial clusters. The mean match scores and standard deviations for singletons and clusters are shown in

Table 4. Age was a significant main effect for both initial singletons, $F(5,842)=32.88, p<.0001, \eta^{2}=.163$, and initial clusters, $F(5,842)=27.91, p<.0001, \eta^{2}=.142$. Initial clusters showed no dialect effect, $F(1,842)={ }_{7} 709, p=4, \eta^{2}=.001$, whereas initial singletons did show a dialect effect, $F(1,842)=6.06, p=.012$, $\eta^{2}=.007$. This effect seems to be completely due to the difference in $/ \delta /$. When the item with $/ \delta /$ was removed from the total matches, dialect was no longer a statistically significant effect, $F(1,842)=.192, p=661, \eta^{2}=.000$.

Testing the asymmetry between initial and final position. Figure 2 shows the similar trajectory of initial and final position for MAE learners from ages 4 to 12 , and similarly, the divergent paths toward mastery for the two word positions in the AAE speakers. A within-subjects ANOVA permitted us to test the reliability of these different patterns across dialect groups. The associated values are provided in Table 7 .

Item type (word position) and item type by dialect were significant within-subject effects; age and dialect were significant between-subject effects, but no interactions were significant. Analyses of simple effects by dialect group confirmed the pattern in

Table 4. Means and standard deviations for correct production of final and initial phonemes and clusters by dialect group.

\begin{tabular}{|c|c|c|c|c|c|}
\hline & \multicolumn{2}{|c|}{$A A E$} & \multicolumn{2}{|c|}{$M A E$} & \multirow[b]{2}{*}{ Mean difference } \\
\hline & $\mathrm{M}$ & $\mathrm{SD}$ & $\mathrm{M}$ & $\mathrm{SD}$ & \\
\hline All final elements (of 54) & 465 & 67 & 51.4 & 44 & 49 \\
\hline Final clusters (of 19) & 15.3 & 312 & 17.9 & 22 & 26 \\
\hline Final singletons (of 35 ) & 30.7 & 39 & 33.6 & 2.4 & 2.9 \\
\hline Final singletons without $/ \delta /$ and $/ \theta /$ (of 31 ) & 28.95 & 30 & 30.3 & 1.7 & 1.35 \\
\hline All initial elements (of 56) & 52.8 & 46 & 53.5 & 5.0 & 0.7 \\
\hline Initial clusters (of 25 ) & 228 & 34 & 23.2 & 39 & 0.4 \\
\hline Initial singletons (of 31 ) & 29.97 & 1.6 & 30.32 & 1.5 & 0.35 \\
\hline Initial singletons without $/ \mathrm{J} /$ (of 30 ) & 29.34 & 1.3 & 2941 & 13 & 0.07 \\
\hline
\end{tabular}


Table 5. Analysis of variance (ANOVA) for all final elements (dependent variable is "match to MAE" score)

\begin{tabular}{lcccc}
\hline & df & F & p & $\eta^{2}$ \\
\hline & & & & \\
Age & 5,767 & 7.9 & $<.0005$ & 049 \\
Dialect & 1,767 & 27.14 & $<.0005$ & .034 \\
Region & 3,767 & 3.37 & 018 & .013 \\
Gender & 1,767 & 99 & .319 & .001 \\
Age $\times$ Dialect & 5,767 & 1.02 & 40 & .007 \\
Region $\times$ Dialect & 3,767 & 1.1 & .35 & .004 \\
Parent Education $^{\mathbf{2}}$ & 4,801 & 1.15 & .34 & .006 \\
Parent Education $\times$ Dialect $\times$ Age $^{14,801}$ & 1.7 & .06 & .028 \\
\hline
\end{tabular}

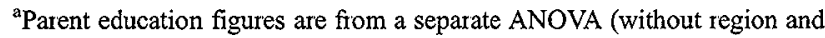
AQ11 gender). (Bonferroni alpha value $=.01$ )

the figures, that item type was highly significant for the AAE group, $F(1,531)=202.74, p<.0001, \eta^{2}=.226$, but not for the MAE group, $F(1,311)=1.419, p=235, \eta^{2}=.005$.

\section{AQ12 H5. The Effect of an Unstressed Initial Syllable}

The DSLT included one pair of items with which to test the effect on the accuracy of a segment from being in an unstressed syllable in initial position (in an iambic word): dusty versus destroy. The /d/ of dusty was at $100 \%$ matches for both groups at age 4 , whereas the /d/ of destroy reached criterion at age 5 for the MAE group and age 6 for the AAE group. AAE children were twice as likely as MAE children not to match the /d/ of destroy ( $10 \%$ vs. $5 \%)$, which is a significant difference by chi-square test: $\chi^{2}(1, N=$ $854)=6.24, p=.012$.

\section{H6. Interdental Fricatives}

We hypothesized that the interdental fricatives, $/ \theta /$ and $/ \delta /$, would be more contrastive than the other phonemes of MAE Of the two, / $/$ / was the more contrastive, as initial $/ \theta /$ was not different for the two groups in initial position (cf. Green, 2002). Thus, unlike $/ \delta /$, the contrast in $/ \theta /$ appeared to follow the phonotactic constraints that were noted for all other consonants in AAE, whereas / $/$ / never reached the MAE-match criterion in either position. This

Table 6. ANOVA for all initial elements (dependent variable is "match to MAE" score).

\begin{tabular}{|c|c|c|c|c|}
\hline & df & F & $\mathrm{p}$ & $\eta^{2}$ \\
\hline Age & 5,767 & 11263 & $<.0001$ & .068 \\
\hline Dialect & 1,767 & 130 & .719 & .000 \\
\hline Region & 3,767 & 1.79 & .15 & .007 \\
\hline Gender & 1,767 & 1.1 & 29 & .001 \\
\hline Age $\times$ Dialect & 5,767 & 1.14 & 34 & .007 \\
\hline Dialect $\times$ Region & 3,767 & 1.2 & 31 & .005 \\
\hline Parent Education ${ }^{a}$ & 4,801 & 85 & 49 & .004 \\
\hline Parent Education $\times$ Dialect $\times$ Age $*$ & 14,801 & 12 & 26 & 021 \\
\hline
\end{tabular}

a Parent education figures are from a separate ANOVA (without region and gender)
Table 7. ANOVA for comparison of contrastive and noncontrastive item type by age, dialect, and region (dependent variable in percents).

\begin{tabular}{|c|c|c|c|c|}
\hline & df & $\mathrm{F}$ & $\mathrm{p}$ & $\eta^{2}$ \\
\hline \multicolumn{5}{|l|}{ Within factor } \\
\hline Item Type & 1,808 & 36.21 & $<.0005$ & 043 \\
\hline Item Type $\times$ Dialect & 1,808 & 32.87 & $<.0005$ & .039 \\
\hline Item Type $\times$ Age & 5,808 & 655 & .65 & .004 \\
\hline Item Type $\times$ Region & 3,808 & 1.54 & 2 & .006 \\
\hline $\begin{array}{c}\text { Item Type } \times \text { Age } \times \text { Dialect } \\
\text { (other interactions not significant) }\end{array}$ & 5,808 & 80 & 55 & .005 \\
\hline \multicolumn{5}{|l|}{ Between factors } \\
\hline Age & 5,808 & 16.129 & $<.0005$ & 091 \\
\hline Dialect & 1,808 & 13.978 & $<.0005$ & 017 \\
\hline Region & 3,808 & 3.098 & .026 & .011 \\
\hline Age $\times$ Dialect & 5,808 & 1.686 & .14 & .010 \\
\hline Dialect $\times$ Region & 3,808 & 1.073 & 36 & .004 \\
\hline Age $\times$ Region & 15,808 & .805 & 67 & 015 \\
\hline Age $\times$ Dialect $\times$ Region & 13,808 & 1.74 & 05 & .027 \\
\hline
\end{tabular}

suggests that the difference between the dialect groups for $/ \delta /$ was not only a question of a difference in the distinct developmental timetables, but in fact a true difference with respect to the phonemic status of / $/$ / within AAE.

\section{H7. Age at Which Dialect Effects Were Seen}

In all of the comparisons of contrastive features, age and dialect were significant effects, and there was no Age $\times$ Dialect interaction. In fact, in an analysis of the simple effect of dialect at the six ages, dialect was a significant effect from age $4, F(1,167)=$ $16.97, p<0001, \eta^{2}=.107$, through age $12, F(1,93)=37.301$, $p<.0001, \eta^{2}=.286$. The effect size increased as the children got older (and the standard error decreased), but the effect was present and discernable from age 4 . For initial consonants, where there was no difference observed between the dialect groups at age 4 , there was no difference at older ages either.

\section{DISCUSSION}

The purpose of this study was to examine the phonological development of larger groups of AAE children learning MAE across wider age ranges than have previously been studied. It was more comprehensive than previous studies in the sense that both segments (consonants) and structures (syllable and word shapes) that were predicted to be both noncontrastive (the same) and contrastive (different) in the two dialects were examined. Parent education level, region, gender, and the ethnicity of the examiner were all ruled out as significant extraneous variables.

Our findings for developmental norms for children learning $\mathrm{MAE}$ as a first dialect are generally in keeping with those of Smit et al. (1990) and with Shriberg's (1993) early 8, middle 8, and late 8 groupings. Those sounds on which our findings differ from Smit's are all late 8 sounds, which tend to vary more in their ages of acquisition, with the exception of $[\mathrm{v}, \mathrm{t} f]$, which are middle 8 sounds. Our results clearly indicate that AAE- and MAE-speaking children showed equivalent pronunciation of most MAE singleton 
consonants and clusters in initial position, but not in final position. The MAE learners showed some differences on a segment by segment basis between initial and final position, but for the AAEspeaking children, the difference in the two positions was more dramatic.

The voiced interdental fricative, $/ \delta /$, proved to be the most contrastive single segment, with production matching the targets occurring several years later in AAE speakers for both initial and final position. It was not acquired by AAE speakers even at the latest age, raising the question of whether $/ \delta /$ should be considered to be within the phonemic repertoire of AAE. In accordance with Green (2002), its voiceless counterpart, / $\theta /$, proved less contrastive, with criterion achieved later than MAE only in final position. Perhaps the fact that the latter occurs in more salient content words decreases the disadvantage for initial $/ \theta /$, whereas the extremely low frequency of $/ \delta /$ in adult AAE increases its challenge for the AAE learners. In this situation, the role of phonetic factors predominated, rendering this segment quite unlikely to match MAE in all positions. Yet, final position remained less advantageous than initial position; thus, phonotactics cannot be ignored as a critical factor even in the case of this highly contrastive segment.

Our results also extend previous reports of earlier mastery of $/ \mathrm{r} /$ in prevocalic position (Seymour \& Seymour, 1981; Stockman, 2006 ) to initial and even final clusters (-rs). The later developing segment $/ \mathrm{s} /$, too, was found to be at criterion earlier for AAE learners not only in initial but also in final position. This is all the more surprising because final/-s/ is often omitted in adult AAE for morphological reasons, so it might appear a more variable element. AAE learners also demonstrated an advantage for $/ z /$ in final position. Other final consonants and final consonant clusters were confirmed as matching MAE targets later in children who were learning AAE first than in those who were learning only MAE, as indicated in many previous studies. Unlike in Craig and Washington (2004), differences were not noted in the production of $/ \mathrm{y} /$ across the two dialect groups, perhaps because of its occurrence in monomorphemic words, where it was less often substituted than in the suffix -ing

Thus, it appears that both rate and order of acquisition of both noncontrastive and contrastive phones differed across the two dialects. Some of the differences identified between the phonological trajectories of the AAE versus the MAE learners (e.g., the accuracy of the initial consonant in an iambic word, several clusters in initial position $[/ \mathrm{s}, \mathrm{z} /, / \mathrm{b}, \mathrm{d} 3,1 /]$ and several clusters in final position) all occurred during the 4- to 5-year-old range, vindicating our decision to extend Craig and Washington's (2004) findings to earlier ages.

\section{Limitations of the Study}

The greatest limitation of this research stems from our reliance on the transcriptions of others-the more than 400 SLPs from around the United States who participated in the standardization of the DELV. The objective of the original study, to find a set of segments and clusters that would not be biased against AAE speakers when they are tested by MAE-speaking SLPs, made it important to use a large number of SLPs who reflect the ethnic composition of the profession. Thus, they add a measure of ecological validity to the methodology. Still, except for a couple of audiotapes that we could compare with the record forms, we had no access to the actual productions of the children, so further reliability procedures were not possible. We had to trust the integrity of the process and the need for accuracy on the part of The Psychological Corporation, which collected the data with great care In addition, the large number of children who were tested, the large number of SLPs who participated, and the consistent effects that were identified diminish the likelihood of this factor having a negative effect on the overall findings of the study. With respect to how representative the findings are, the results of the substudy where the ethnicity of the examiner was tested suggest that the findings are most robust for the noncontrastive elements and less so for the contrastive elements. It is likely that our methodology underestimates the difference between the dialect groups on the contrastive elements, but does not undermine the relative timetable provided as a useful guide for both AA and non-AA SLPS.

A second limitation concerns the small effect sizes that were found even for statistically significant variables whose $F$ values have very small probability. One might be tempted to conclude that the differences between the age and dialect groups are not random, but of no great importance. However, we submit that although they are small in the context of explaining all of the variance in the analysis, the differences in the means, especially between the two dialect groups, have great practical implications There is every reason to think that the groups were equivalent in their phonological maturity, as they were equivalent when tested in initial position, even on difficult segments and clusters. The means and distributions around the means were very similar. Judging from initial position, the MAE children cannot be said to be more adept in articulation in general than the AAE children. However, as shown in Table 4, the difference between the mean scores in final position approached a full standard deviation. If the means in final position were viewed from the perspective of the distributions around them, one would see that $15 \%$ more AAE than MAE children $(20 \%$ vs. $5 \%)$ had scores that were $1 S D$ below the group mean, and $7 \%$ more $(7.8 \%$ vs. $0.6 \%)$ had scores that were $2 S D$ s below the group mean. Depending on the criterion one chose to indicate atypical performance, in this sample of 854 children, the skills of $107(20 \%)$ or $36(7.8 \%)$ of the 534 AA children would be underestimated relative to the non-AA children, even if the mean differences between the groups were relatively small.

If one uses the reasoning that has been seen in discussions of health disparities, the potential importance of a "small" effect may be better appreciated According to Scanlan (2006), the statement of the comparison between two groups' likelihood of avoiding a disease and of experiencing it is dramatically different depending on which perspective one takes. If a disease is rare, relatively few people in either group will have it, and so the high probability of not having the disease will be similar in the two groups. Viewed from the other perspective, however, the likelihood of contracting the same rare disease will be more disparate. That is the case here with these two groups of typically developing children. Most of the children, in both groups, are within the average range, whether one chooses $1 S D$ or $2 S D$ s below the mean as a cutoff for atypical performance. The difference in avoiding the "atypical" label is relatively small. Even in final position where there is a distinct difference in the number of children who are susceptible to being labeled atypical, the disparity in avoiding the label is relatively small Eighty percent of AAE children and $95 \%$ of MAE children were above $1 S D$ below the mean, which is a criterion for phonological impairment that is sometimes used for qualifying for services (Mercer, Jordan, Allsopp, \& Mercer, 1996), so the AA 
likelihood of not being so labeled is $80 / 95$, or $84 \%$ of the MAE likelihood. By contrast, the same disparity is realized more dramatically when one describes the different likelihoods of experiencing the label. Twenty percent versus the MAE 5\% tells us that AAE children are four times more likely to be labeled atypical if the criterion is $1 S D$ below the mean. If the criterion is $2 S D$ s below the mean, the disparity in the likelihoods becomes $7.8 \%$ versus $0.6 \%$, or 12 times more likely for the AA children

It was important to have a large number of participants in order to have enough power to test several factors at once, and also to be able to generalize the main results. But by having such large numbers, more variability is introduced from other factors, and effects that have real-life consequences were diminished relative to the larger picture. The effect size was thus small statistically, but those consequences are nonetheless very important

Another limitation is the fact that, in order to increase the difficulty level of the phonological component of the DSLT and DELV, later developing clusters, especially clusters with $/ \mathrm{r} /$, were oversampled. Furthermore, discrimination testing was not carried out, so it is not possible to be certain what the children's underlying representations are for the segments and structures tested Some indication is available that clusters that were reduced in final position were represented in full, given that they are more likely to be produced in full when a suffix is added (e.g., cold vs. coldest) (Pearson, Velleman, Bryant, Abdulkarim, \& Seymour, 2004). Further support for this claim might have been available had medial position been tested systematically.

A related weakness is the fact that some final consonants and clusters in this study were tested in prevocalic or preconsonantal contexts whereas others were assessed in sentence-final position. In some cases, these contextual factors had a measurable impact; in others, the results were resistant to this factor. (See the superscripts in the Appendix.) In several cases, it cannot be determined whether they may have impacted our results. For example, /r/ was acquired earlier in final position by AAE speakers despite the fact that one out of three final $/ \mathrm{r}$ / stimuli was preconsonantal, and two were in the less favored unstressed syllable Similarly, $/ \mathrm{y} /$ was acquired at the same age by both groups of children despite its occurrence only preconsonantally and despite previous reports to the contrary (i.e., Craig \& Washington, 2004). On the other hand, postvocalic /-g/,/-k/,/-ld/, /-ft/, and /-rd/ all occurred preconsonantally only, and all of these segments or segment combinations were mastered later by the AAE-speaking children This finding is consistent with previous research, but the actual impact of context on these final segments and clusters cannot be evaluated within our study.

Another weakness in the study is the assumption made almost throughout that both MAE and AAE are unitary dialects with similar features all across the United States. There was some suggestion that the $9 \%$ of the MAE speakers who were from the West behaved somewhat differently than the other MAE speakers. Because no differences by region were identified for the AAE speakers who are the focus of this study, this factor was not controlled in the rest of the analyses, but it may have had some subtle effects on the outcomes that we are not aware of

\section{Future Research}

Issues for future research include exploring the interactions between phonotactics and phonetics in children's error patterns depending on which is their first dialect: It will be useful, too, to extend these findings to even lower ages, seeking potential differences in the emergence (i.e., first productive use) of phonetics (segments) versus phonotactics (structures) in the two dialects. We are also in the process of carrying out similar analyses of the speech production of the phonologically impaired AAE and MAE learners in the DSLT/DELV standardization sample to determine whether mismatch patterns differ in the same ways. For both typical populations and those with language impairments, more finegrained analysis of mismatches, focusing for example on varying substitution patterns (fronting, gliding), would also be of great interest.

\section{CLINICAL IMPLICATIONS}

These findings have critical clinical implications. Both segmental and phonotactic development show different trajectories for AAE than for MAE first-dialect speakers. A deficit model, with a focus on only those elements (e.g., /ठ/, / $/$ /) and structures (e.g., final consonants and consonant clusters) that reach a criterion for matching MAE later by AAE speakers, is clearly inappropriate. Conversely, learners of AAE may be expected to produce certain elements (e.g., /r/, /s/, /z/) and structures (e.g., several initial clusters) in the MAE manner at the same or at earlier ages than first-dialect learners of MAE. Thus, these noncontrastive, shared phonological elements and structures are useful for assessing disorders in AAE populations who are learning MAE. An AAEspeaking child who has difficulty with $/ \mathrm{r} /, / \mathrm{s} /, \mathrm{z} /$, or initial liquid clusters or clusters with $/ \mathrm{s} /$ (other than $/ \mathrm{skr}-/$ and $/ \mathrm{s} \mathrm{x} /$ ) should be assessed carefully to determine whether or not a phonological delay or disorder is present. On the other hand, an AAE-speaking child whose only errors affect / $/$ / should not be targeted for further assessment or remediation. The best possible approach is to use a standardized test that is not biased against children who speak AAE, such as the DELV.

With respect to treatment, goal ordering should match the milestones reported in Table 3 for each dialect. In particular, although recent research has suggested that some typically developing MAE-speaking children acquire homorganic final clusters at the same time or earlier than the earliest stop + glide initial clusters (Dyson, 1988; Kirk \& Demuth 2003; McLeod et al., 2001a; Watson \& Scukanec, 1997), final clusters should not be considered an appropriate early cluster remediation target for children whose first dialect is AAE On the other hand, other targets that may be seen as premature for an MAE-speaking child may be timely for an AAE speaker. Specifically, $/ \mathrm{t} /, / \mathrm{s} /$, and $/ \mathrm{z} /$, in either initial or final position, and two-element initial clusters that include these segments would be appropriate goals as early as 6 years of age for a phonologically disordered child who is acquiring $A \mathrm{AE}$.

\section{ACKNOWLEDGMENTS}

This work was funded in part by the National Institute on Deafness and Other Communication Disorders under Contract N01 DC8-2104 to Harry Seymour, Principal Investigator at the University of Massachusetts, Amherst, with Thomas Roeper and Jill de Villiers at UMass and Smith College as co-investigators and Barbara Pearson as Project Manager. It was 
accomplished in conjunction with The Psychological Corporation of Harcourt Assessments, Inc., now Pearson Education, Inc of San Antonio, IX, Lois Ciolli, Senior Research Director Data and selected extracts of the phonology subtest from the DELV/DSLT were used by permission of the publisher ("Diagnostic Evaluation of Language Variation" and "DELV," copyright c 2003, are trademarks of Pearson Education Inc. or its affiliates.) Funding was also provided by National Science Foundation Grant BCS-0318135 to Shelley Velleman, Principal Investigator at the University of Massachusetts, Amherst

\section{REFERENCES}

Bailey, G., \& Thomas, E. (1998). Some aspects of African-Ametican Vernacular English phonology. In S. Mufwene, J. R. Rickford, G. Bailey, \& J. Baugh (Eds ), African-American English Structure, history, and use (pp. 85-109). New York: Routledge.

Chambless, D. (2006) Asymmetries in the acquisition of consonant clusters Unpublished doctoral dissertation, University of Massachusetts, Amherst.

Craig, H. K., Thompson, C. A., Washington, J. A., \& Potter, S. L. (2003) Phonological features of child African American English. Journal of Speech, Language, and Hearing Research, 46, 623-635

Craig, H. K., Thompson, C. A., Washington, J. A., \& Potter, S. L. (2004) Performance of elementary-grade African American students on the Gray Oral Reading Tests. Language, Speech, and Hearing Services in Schools, 35, 141-154

Craig, H. K., \& Washington, J. A. (2002) Oral language expectations for African American preschoolers and kindergartners. American Journal of Speech-Language Pathology, 11, 59-70

Craig, H. K., \& Washington, J. A. (2004) "Grade-related changes in the production of African American English Journal of Speech, Language, and Hearing Research, 47, 450-463.

Craig; H. K., Washington, J. A., \& Thompson-Porter, C. (1998). Average $\mathrm{C}$-unit lengths in the discourse of African American children from low income, urban homes Journal of Speech, Language, and Hearing Research, 41, 433-444.

AQ14 Cukor-Avila, P., \& Bailey, G. (2001). The effects of the race of the examinet on sociolinguistic fieldwork Journal of Sociolinguistics, 5(2), $254-271$.

de Villiers, P. A., Burns, F., \& Pearson, B. Z. (2005). Narrative language and theory of mind acquisition. Effects of development, clinical status and dialect Unpublished manuscript, University of Massachusetts

AQ15 Amherst and Smith College, Amherst and Northampton, MA

Docherty, G. J., Foulkes, P., Tillotson, J., \& Watt, D. (2006). On the scope of phonological learning: Issues arising from socially structured variation. In L. Goldstein, D. H. Whalen, \& C. T. Best (Eds ), Laboratory phonology 8 (pp. 341-366). Berlin: Mouton de Gruyter

Dyson, A. (1988). Phonetic inventories of 2- and 3-year-old children Journal of Speech and Hearing Disorders, 53, 89-93.

AQ16 Edwards, M. L. (1996). Word position effects in the production of fricatives. Paper presented at the UBC International Conference on Phonological Acquisition, Vancouver, BC

Farwell, C. (1977). Some strategies in the early production of fricatives Papers and Reports in Child Language Development, 12, 97-104.

Fasold, R. W. (1981). The relation between Black and White speech in the South American Speech, 56(3), 163-189.

Ferguson, C. A., \& Farwell, C. B. (1975). Words and sounds in early language acquisition Language, 51, 419-439.

Green, L. J. (2002) African American English A linguistic introduction. New York: Cambridge University Press
Haynes, W. O., \& Moran, M. J. (1989) A cross-sectional developmental study of final consonant production in southern Black children from preschool through third grade Language, Speech, and Hearing Services in Schools, 20, 400-406

Hinton, L. N., \& Pollock, K. E. (2000). Regional variation in the phonological characteristics of African American Vernacular English. World Englishes, 19(1), 39-58.

Horton-Ikard, R., \& Miller, J. (2004) It is not just the poor kids: The use of AAE forms by African-American school-aged children from middle SES communities. Journal of Communication Disorders, 37(6), 467-487

Ingram, D. (1978). The role of the syllable in phonological development In A. Bell \& J. Hooper (Eds), Syllables and segments (pp. 143-155) Amsterdam: North Holland

Jackson, J., \& Pearson, B. Z. (2004) Contrastive versus non-contrastive AQ17 features in African American English child speech, ages 4-12. Poster presented at the annual meeting of the American Speech-LanguageHearing Association, Philadelphia, $\mathrm{PA}$

Kent, R. D. (1982). Contextual facilitation of correct sound production. Language, Speech, and Hearing Services in Schools, 13, 66-76

Kirk, C., \& Demuth, K. (2003). Coda/onset asymmetries in the acquisition of clusters. In B. Beachley, A Btown, \& F Conlin (Eds), Proceedings of the Boston University Conference on Language Development 27 (pp. 437-448) Somerville, MA: Cascadilla Press

Labov, W. (1970). The logic of non-standard English. In F. Williams (Ed), Language and poverty (pp. 153-189) Chicago: Markham

Laing, S. P. (2003). Assessment of phonology in preschool African American Vernacular English speakers using an alternate response mode American Journal of Speech-Language Pathology, 12, 273-281

Linnes, K. (1998). Middle-class AAVE versus middle-class bilingualism: Contrasting speech communities. American Speech, 73(4), 339-367.

Luelsdorff, P. A. (1975) A segmental phonology of Black English. The Hague: Mouton

McLeod, S., van Doorn, J., \& Reed, V. A. (2001a) Consonant cluster development in two-year-olds: General trends and individual differences. Journal of Speech, Language, and Hearing Research, 44, 1144-1171

van Doorn, J., \& Reed, V. A. (2001b) Normal acquisition of consonant clusters. American Journal of Speech-Language Pathology, 10, 99-110.

Mercer, C. D., Jordan, L., Allsopp, D. H., \& Mercer, A. R. (1996) Learning disabilities definitions and criteria used by state education departments. Learning Disability Quarterly, 19(4), 217-232.

Moran, M. (1993). Final consonant deletion in African American children speaking Black English: A closer look. Language, Speech, and Hearing Services in Schools, 24, 161-166

Pearson, B. Z., Velleman, S., Bryant, T. J., Abdulkarim, L., \& Seymour, H. (2004, May). Development of contrastive and non-contrastive phonological features in African-American English learning children, ages 4 to 12. Paper presented at the Child Phonology Conference, Tempe, AZ.

Peña-Brooks, A., \& Hegde, M. N. (2000). Assessment and treatment of articulation and phonological disorders in children. Austin, IX: Pro-Ed.

Pollock, K., Bailey, G., Berni, M..C., Fletcher, D. G., Hinton, L. N., Johnson, I. A., et al. (1998). Phonological features of African American Vernacular English. Retrieved April 7, 2008, from http://www. rehabmed. ualberta ca/spa/phonology/features htm

Pollock, K., \& Berni, M. C. (1996). Vocalic and postvocalic /t/ in African AQ18 American Memphians. Paper presented at the meeting of New Ways of Analyzing Variation in English (NWAVE), Las Vegas.

Pollock, K., \& Berni, M. C. (1997). Acquisition of /r/ by African American AQ19 and European American children. Paper presented at the annual convention of the American Speech-Language-Hearing Association, Boston, MA. 


\section{LSH4003_Pearson (1st Proof)}

Ratusnik, D. L., \& Koenigsknecht, R. A. (1976). Influence of age on Black preschoolers' nonstandard performance of certain phonological and grammatical forms. Perceptual and Motor Skills, 42, 199-206.

Rickford, J. R. (1999). African American Vernacular English. Features, evolution, educational implications. Malden, MA: Blackwell

Roberts, J. (1997) Acquisition of variable rules: A study of (-t, -d) deletion in preschool children Journal of Child Language, 24(2), 351-372

Roberts, J. (2006) As old becomes new: Glottalization in Vermont. American Speech, 81(3), 227-249.

Scanlan, J. P. (2006) Can we actually measure health disparities? Chance, $19(2), 47-51$

Seymour, H. (2004) A noncontrastive model for assessment of phonology. Seminars in Speech and Language, 25(1), 91-100

AQ20 Seymour, H., Green, L., \& Huntley, R. (1991). Phonological patterns in the conversational speech of African American children. Paper presented at the annual convention of the American Speech-Language-Hearing Association, Atlanta, GA

Seymour, H., Roeper, T., \& de Villiers, J. G. (2000, unpublished). Dialect Sensitive Language Test (DSLT). Unpublished manuscript

Seymour, H., Roeper, T., \& de Villiers, J. (2003) Diagnostic Evaluation of Language Variation Screening Test. San Antonio, TX: The Psychological Corporation.

Seymour, H., Roeper, T., \& de Villiers, J. (2005) Diagnostic Evaluation of Language Variation -Norm-Referenced Test (DELV-NR). San Antonio, IX: The Psychological Corporation.

Seymour, H., \& Seymour, C. M. (1977). A therapeutic model for com-

AQ21 municative disorders among Black English speaking children. Journal of Speech and Hearing Disorders, 42, 247-256

Seymour, H., \& Seymour, C. M. (1981). Black English and Standard

AQ22 American English contrasts in consonantal development of four and five-year-old children. Journal of Speech and Hearing Disorders, 46, $276-280$

Shriberg, L. D. (1993). Four new speech and prosody measures for genetics research and other studies in developmental phonological disorders Journal of Speech and Hearing Research, 36, 105-140

Smit, A.-B., Hand, L., Freilinger, J. J.,-Bernthal, J. E., \& Bird, A. (1990): The Iowa atticulation norms project and its Nebraska replication. Journal of Speech and Hearing Disorders, 55, 779-798.

Stockman, I. (1993) Variable word initial and medial consonant relationships in children's speech sound articulation. Perceptual and Motor Skills, 76, 675-689

Stockman, I. (1996) Phonological development and disorders in African American children In A G Kamhi, K E Pollock, \& I. L. Harris (Eds.), Communication development and disorders in African American children. Research, assessment, and intervention (pp. 117-153). Baltimore: Brookes.
Stockman, I. (2006). Evidence for a minimal competence core of consonant sounds in the speech of African American children: A preliminary study Clinical Linguistics \& Phonetics, 20(10), 723-749

Stockman, I., \& Vaughn-Cooke, F. B. (1989). Addressing new questions about Bláck children's language. In R. W Fasold \& D. Schriffrin (Eds.), Language change and variation (pp. 275-300). Amsterdam: John Benjamins

Stoel-Gammon, C. (1996). On the acquisition of velars in English. In B. Bernhardt, J. Gilbert, \& D. Ingram (Eds.), Proceedings of the UBC International Conference of Phonological Acquisition (pp 201-214). Somerville, MA: Cascadilla Press

U.S. Bureau of the Census. (2000). Current population survey, October 2000: School enrollment supplemental file [CD-Rom]. Washington, DC: Author.

Vaughn-Cooke, F. B. (1987) Are Black and White Vernaculars diverging? American Speech, 62, 12-32

Velleman, S. (1998). Making phonology functional: What do I do first? Boston: Butterworth-Heinemann.

Velleman, S. L., \& Shriberg, L. D. (1999). Metrical analysis of children with suspected developmental apraxia of speech and inappropriate stress. Journal of Speech, Language, and Hearing Research, 42(6), 1444-1460.

Vihman, M. M., \& Hochberg, J. G. (1986). Velars and final consonants in early words. In I A Fishman, A Tabouret-Keller, M. Clyne, B Krishnamurti, \& M. Abdulaziz (Eds.), The Fergusonian impact Volume 1. From phonology to society (pp. 37-49). Berlin: Mouton de Gruyter:

Watson, M. M., \& Scukanec, G. P. (1997). Profiling the phonological abilities of 2-year-olds: A longitudinal investigation. Child Language Teaching and Therapy, 13(1), 3-14.

Wolfram, W. (1991). Dialects and American English. Englewood Cliffs, NJ: Prentice Hall

Wolfram, W. (1994). The phonology of a sociocultural variety: The case of African American Vernacular English. In J. E. Bernthal \& N. W. Bankson (Eds.), Child phonology: Characteristics, assessment, and intervention with special populations (pp. 227-244). New York: Thieme Medical

Received June 9, 2008

Revision received August 19, 2008

Accepted September 16, 2008

DOI: $10.1044 / 0161-1461(2008 / 08-0064)$

Contact author: Barbara Zuror Pearson, University of Massachusetts, Amherst, Departments of Linguistics and Communication Disorders, South College 226, Amherst, MA 01003. E-mail: bpearson@research umass edu 
APPENDIX (P. 1 OF 2). TARGETS TESTED IN THE DIALECT SENSITIVE LANGUAGE TEST (SEYMOUR, ROEPER, \& de VILLIERS, 2000)

Table 1. Singleton consonant targets by word position

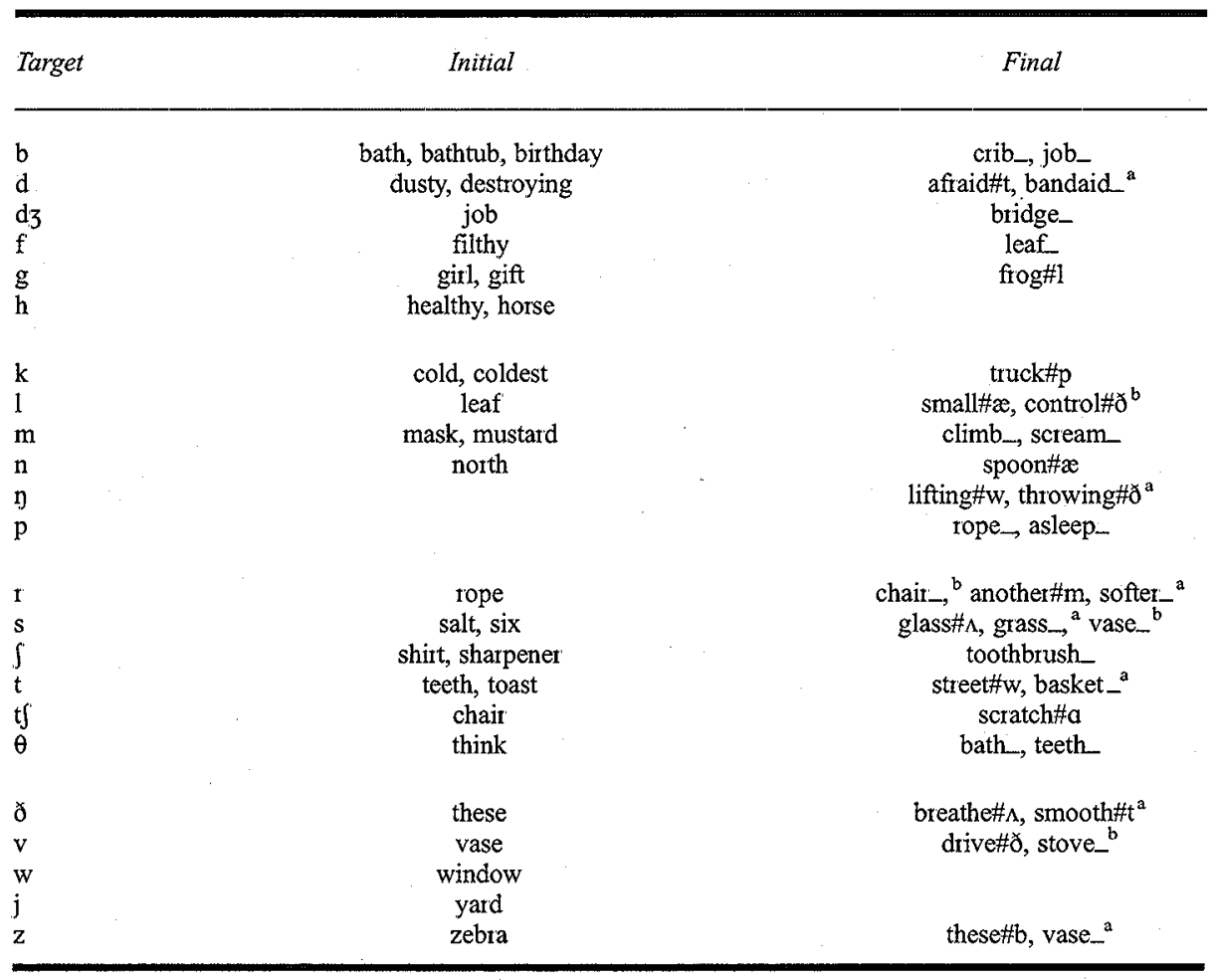

Note. Consonants and clusters in final position are marked according to the following vowel, consonant, or pause, as follows:

CHC: followed by a $C$ (specified e g., “afraid\#t" indicates the the final $/ \mathrm{d} /$ of "afraid" was followed by a $/ \mathrm{t} /$ at the onset of the next word - "to", in this case - in the sentence to be imitated)

$\mathrm{CHV}$ : followed by a vowel (vowel specified, as described above)

C\#_: sentence-final position (e.g., "crib_" means the final /b/ in "crib" was sentence-final)

aDenotes nonsignificant $\chi^{2}$ comparison, ${ }^{b}$ denotes significant $\chi^{2}$ comparison 
APPENDIX (P. 2 OF 2). TARGETS TESTED IN THE DIALECT SENSITIVE LANGUAGE TEST (SEYMOUR, ROEPER, \& de VILLIERS, 2000)

Table 2. Consonant clusters by position.

\begin{tabular}{|c|c|c|}
\hline Target & Initial & Final \\
\hline br & breathe, bridge & \\
\hline $\mathrm{dr}$ & drive & \\
\hline fr & Frog & \\
\hline $\mathrm{ft}$ & & gift\#n \\
\hline $\mathrm{gl}$ & Glass & \\
\hline $\mathrm{gr}$ & grass & \\
\hline $\mathrm{kl}$ & climb & \\
\hline $\mathrm{kr}$ & crib & \\
\hline ks & & six \\
\hline ld & & cold_b \\
\hline it & & salt \\
\hline $\mathrm{mp}$ & & shrimp \\
\hline nk & & skunk, think\# ${ }^{b}$ \\
\hline nt & & plant\#n, present_a \\
\hline $\mathrm{pl}$ & plant & \\
\hline pr & present & \\
\hline $\mathrm{rd}$ & & yard \\
\hline If & & scarf\#æ \\
\hline $\mathrm{xl}$ & & $\operatorname{girl} \# \mathfrak{x}$ \\
\hline rs & & horse_ \\
\hline it & & shirt\#f, smatt\#f \\
\hline $\mathrm{r} \theta$ & & north \\
\hline $\mathrm{fr}$ & shrimp & \\
\hline sk & skunk, scaIf & mask__ \\
\hline skt & scratch, scream & \\
\hline $\mathrm{sm}$ & small, smart, smooth & \\
\hline $\mathrm{sp}_{\mathrm{spl}}$ & $\begin{array}{l}\text { spoon } \\
\text { splash }\end{array}$ & $\ldots \ldots \ldots+\cdots$ \\
\hline $\begin{array}{l}\text { spl } \\
\text { st }\end{array}$ & $\begin{array}{l}\text { splash } \\
\text { stove }\end{array}$ & toast\#ة, dentist\#ة \\
\hline str & street & \\
\hline$\theta \mathbf{r}$ & throwing & \\
\hline $\operatorname{tr}$ & truck, tractor & \\
\hline
\end{tabular}

${ }^{a}$ Denotes nonsignificant $\chi^{2}$ comparison, ${ }^{b}$ denotes significant $\chi^{2}$ comparison. 